with a strictly controlled media. Academic freedom in the universities was restricted. There were few outlets for people to express their opposition to those in power, and in any case political expression courted arrest. Yet, both Iran and Indonesia have active middle classes and fairly high literacy rates, the basis for a civil society.

Students in these countries, and in many other Third World nations, were the only group in society able to express dissenting views. Students in developing countries, after all, come from relatively affluent and urbanized families. They are relatively easy to organize since they are on campus. The academic atmosphere, even in repressive societies such as Iran and Indonesia, is more liberal than in the surrounding society. Perhaps most important, higher education encourages inquiry and the questioning of established practices and institutions. It is not at all surprising that critical opinion will be expressed first among students.

In both countries, unrest spread quickly from the major universities in the capital and attracted the support of significant parts of the urban population. In Indonesia, the rot in the regime was sufficiently deep and social discontent, stimulated by the expanding economic crisis, strong enough to make repression impossible. Suharto was eventually forced to seek a peaceful solution to the crisis and to resign. The students did not achieve their intended goalthe ouster of the entire regime, since Suharto's successor, Habibie, was part of the old regime, and elections did not take place for a year.

In Iran, the conservative leadership was able to bring its own supporters out onto the streets and to dominate the mass media. The regime, through moderate levels of repression and the mobilization of its own supporters, proved that it retained a wellspring of support in society. In both countries, events are still evolving, and students may again play a central role.

Students precipitated the crisis, yet were unable to control events. This too is a common characteristic of student activism. Students have neither the power nor the organizational sophistication to maintain their movement and impose their will on society. Once the crisis takes place, other forces emerge. Often, the military seizes power, or political coalitions are able to cobble together a regime. In Indonesia, the political parties are slowly moving toward creating a government following recent elections. In Iran, the conservative Islamic clerics have, at least for the present, kept power.

University students are a powerful force in many countries. They both shape and express public opinion and cultural attitudes. Often at the forefront of political and social change, they deserve to be understood-and respected.

Note: This article also appears in Change (SeptemberOctober, 1999).

\section{The Academy and the Public Realm}

\section{Zelda F. Gamson}

Zelda F. Gamson is senior associate, New England Resource Center for Higher Education. Address: New England Resource Center for Higher Education, University of Massachusetts, Boston MA 02105, USA. Email: <gamson@umbsky.cc.umb.edu>.

W That is meant by the "public realm?" There is quite a literature on this question. At its base, the public realm is a place and a process whereby citizens become engaged in public life. This engagement can be passive, as in voting for officials who are expected to represent the interests of the citizenry, or it can be active, as in participating in decisions that affect citizens' lives. The forms of expression in the public realm can include formal decision making, rational arguments presented by knowledgeable people, debate, discussion, and storytelling. Participants can be experts and ordinary citizens, activists and nonactivists. Issues up for discussion can include questions of general public concern or they can be of concern to certain groups or a certain locale.

Why is the public realm so important? Most of us recognize that political life in the United States (and many other nations) is in some trouble. Some social scientists see a decline in participation in civic organizations, marked by a decline in membership in voluntary groups. Others have pointed out that while membership in the traditional organizations may have indeed declined a new kind of citizenship is on the rise. Sociologists Carmen Sirianni and Lewis Friedland point to growing participation in grassroots problem-solving activities, "civic innovations," such as the healthy communities movement and local efforts to counter youth violence. There are counterparts to these innovations in other countries among nongovernmental organizations, many of them founded and headed by women.

Modern Tocquevillians do see a breakdown in civic life that cannot be captured by statistics about volunteer activities and local participation. Some argue that the overemphasis on individual choice and personal development undermines deeper social commitments. The fragmentation of society into groups based on class, religion, gender, sexual orientation, race, and ethnicity-argue commentators like Jean Bethke Elshtain and Todd Gitlin-weakens efforts to forge shared commitments among people who have more in common than they think.

I am convinced that the reason for the decline of civic life does not lie with ordinary citizens, who have shown tremendous creativity and good sense in the way they have engaged in public life. Rather, the problem lies with elites and their institutions. Wealthy people across the globe have gone their own way, reaping the benefits of their position 
without regard for the less privileged. This has led to the decline of the middle class-traditionally the carriers of civic life-and a growing gap between the rich and everyone else.

Add to the elites of wealth the elites in the media and government, who have increasingly separated themselves from the general public, and it would appear that civic life is in trouble because the people and organizations with the greatest power and resources have trashed democracy.

\section{Some social scientists see a decline in participation in civic organizations, marked by a decline in membership in voluntary groups.}

\section{The Academy and the Public Realm}

What are the responsibilities of the academy in all this? First, we must look at the university as a public realm. Asking whether and how the university is a public realm is not an obvious question, because academic institutions have both public and nonpublic aspects. There is no doubt that higher education is a public issue. Accountability discourses about higher education have been common and growing in nations around the world and show no sign of abating.

It is unequivocally clear that colleges and universities provide "public space" for citizens and organizations to meet on neutral ground to learn about and discuss issues of public concern. Almost all American colleges and universities do this, whether by inviting the public to lectures, holding open meetings for electoral candidates, organizing forums on civic issues, or convening groups.

What if we ask whether, in addition to serving as a public space, the academy works in and for the public sphere? Here, I think we are likely to encounter skepticism among faculty members and administrators in the United States. This is because the "academic revolution" described in the late 1960s by Christopher Jencks and David Riesman, in which distinctive local and regional institutions turned into less distinctive and more national ones, has drawn faculty and administrators away from the communities in which they reside. This is especially true for elite private universities.

Despite these countervailing forces, faculty involvement in the public sphere in most U.S. colleges and universities is quite high. A survey of all the colleges and universities in New England turned up the rather surprising information that a lot of faculty are involved in such activities. We found this to be true across the spectrum of higher education in the United States.
What faculty members did varied according to the settings in which they worked. Some were consulting with government agencies, businesses, and other organizations that had a connection to the public realm. Others were using their expertise to provide service to organizations like schools and social service agencies.

But while we found a lot of public work engaged in by academics in the United States, we did not find many universities that supported them in that work. Some institutions, research universities and their many imitators, made it hard for faculty to do public work by devaluing it as not being "real" scholarship. As a result, most faculty members are doing these things in spite of their institutions, working around tenure and promotion standards, fitting the work into already overcrowded schedules, trying to integrate it with their teaching and research. Under these conditions, the miracle is that so many faculty are as involved as they are in public work.

The real problem is with the institutions themselves. In our research, my colleagues and I found that generalized support for public scholarship among administrators is very high. However, when we asked specific questions about structures, resources, and rewards in support of this emphasis, much smaller percentages of institutions showed concrete support. The result is that the efforts of individuals on campuses are privatized, invisible, isolated, uncoordinated, and not strategic.

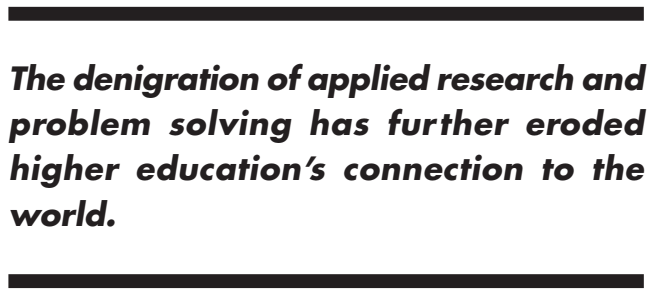

College presidents in the United States are talking a lot nowadays about the need to increase the university's contributions to society. In this they are essentially following the lead of the business world, where even companies that are not considered enlightened encourage their employees to be involved in their communities. Corporations do so not out of superior morality but because they think it is good for business. College presidents are beginning to recognize the public relations value of public service.

I think it is necessary to go back to some of the ideas about the university as a public realm. And it is here that we must start if we are serious. If we are really honest, we would have to admit that the public realm in the academy is impoverished. The traditional research culture that so many institutions have imitated in their quest for prestige and resources is a vampire that saps the blood of younger 
and older faculty alike. By drawing faculty away from commitment to their institutions and communities, the research culture has broken up whatever community existed within the academy and whatever connections the academy had with the public realm in the past.

The denigration of applied research and problem solving has further eroded higher education's connection to the world. The fetishism of much academic writing has contributed to the unintelligibility of academic discourse. The domination of research and publication in tenure and promotion decisions in colleges and universities that are not themselves research institutions has had a chilling effect on the faculty who do engage in the public realm. I am not advocating that faculty stop doing research and stop publishing. Far from it. But they need to do this work in settings that enable - even force- them to ask whether what they are doing contributes to the public realm. We need to ask that question again, and we need to re-create our universities to make that question central.

Note: This article is adapted from a longer article published in The Academic Workplace 10, no.1 (spring 1999): 6-11.

\section{Student-Based Higher Education Financing Policies}

\section{Arthur M. Hauptman}

Arthur M. Hauptman is a public policy consultant based in Arlington, Virginia, specializing in higher education finance issues. His e-mail address is <hauptman@erols.com>.

$\mathrm{P}$ olicymakers and stakeholders around the world are increasingly discussing the desirability of making public policies for higher education based more on the needs of students and less on the needs of institutions. There is considerable variation among countries in how studentbased and institution-based policies are defined. This article looks at one definition of the issue as it applies to the three major elements of financing higher education: government allocations to institutions, tuition fees, and student aid.

\section{Government Allocation Procedures}

The way in which governments allocate taxpayer funds to institutions is the principal public policy vehicle for higher education around the world. In virtually all countries, the distribution of funds to institutions is based on historical patterns, political considerations, or formulas that take into account the number of students enrolled and costs per student at different institutions. Each of these allocation policies is institution based in that the budgetary needs of institutions are uppermost in the determination. Also, very few countries differentiate among the characteristics of enrolled students in determining these allocations.

Government allocation procedures for higher education could be made more student based by factoring student characteristics into the formula for distributing funds. Thus, governments might pay institutions more for the disadvantaged students they enroll than for the more mainstream students. Another example of student-based allocation policies is for governments to pay more for students enrolling in high-priority fields than for those in other fields of study. England is perhaps the best example of a country that has moved to a student-based allocation system in which government allocations are determined more by the price the government is willing to pay for certain groups of students than by the cost of educating those students.

\section{Tuition Setting Policies}

Many higher education participants and observers would say that the fee policy most attuned to the needs of students was one in which the education was provided for free and the government picked up the whole bill. But what is missing in this formulation is that a policy of no fees benefits only the students who are enrolled. For qualified students who cannot enroll because there are not enough seats to accommodate them, a no-fees policy is distinctly not student based. A consequence of having no fees may be that the government can fund fewer spaces (because each subsidized space costs more). Put another way, a nofee policy is student based only if the government provides enough financial support to institutions to create a sufficient supply of seats to meet the demand of qualified applicants.

\section{The way in which governments allocate taxpayer funds to institutions is the prin- cipal public policy vehicle for higher education around the world.}

Most countries that charge fees now adhere at least in theory to a cost-recovery formula by which fees are set as a percentage of the educational costs per student. But like government allocation cost-recovery formulas, fees set as a percentage of costs per student are by definition institution based because they are designed to recover the cost to the institution. An example of a more student-based policy is one in which fees are set in relation to an economic indicator such as GDP per capita or median family 